\title{
Computerized Glucose Clamp Method for the Determination of Insulin Sensitivity in Diabetic Subjects
}

\author{
Mariko Harada, Yutaka Harano, Hideto Kojima, Masaaki Suzuki, \\ Shunichi Furusawa, Yoshihiko Nishino, Takatoshi Uchigaki*, \\ Hiroshi Hyodo* and Yukio Shigeta
}

\begin{abstract}
A new, simplified computerized glucose clamp method was performed for estimation of glucose utilization at the insulin level of postprandial level. The program for the method is based on the mathematical algorithm using values of blood glucose, changes of its concentrastion and the desired glucose level. The coefficients of variation of the clamped blood glucose values during the last 60 minutes was $6.3 \pm 1.7(\%)$ in normal, $3.7 \pm 0.3(\%)$ in NIDDM, which was within satisfactory limit, and also indicated an attainment of steady state. Glucose infusion curves showed some bumps for the initial $60 \mathrm{~min}$, which did not seriously affect the glucose utilization rate at steady state. In some cases, whose insulin sensitivity was high, $\mathrm{CV}$ was not low enough and occasional manual adjustment of $\mathrm{K}$ values was required. Average glucose infusion rate was $7.59 \pm 0.85(\mathrm{mg} / \mathrm{kg} / \mathrm{min})$ in normal, and this was significantly lowered in NIDDM $(42.3 \pm 3.4)$ at steady state, indicating a decreased insulin sensitivity for glucose utilization in NIDDM.
\end{abstract}

Key Words: Insulin sensitivity, Computerized glucose clamp method, Insulin action in man, NIDDM, Glucose utilization

Insulin resistance is a predominant feature of the patients with type II diabetes mellitus ${ }^{1,2)}$. Various attempts have been done for the estimation of insulin sensitivity by many investigators. Shen et al. ${ }^{3)}$ has introduced a reliable method of quantifying insulin resistance by a constant infusion technique of glucose, insulin, propranolol and epinephrine. They documented the presence of insulin resistance in patients with type II diabetes. One obvious drawback to this method is the need of infusing propranolol and epinephrine. Harano et al. ${ }^{4,5,7)}$ has developed a method using somatostatin instead of propranolol and epinephrine. This method has enabled us to obtain SSPG more accurately by suppressing GH, glucagon and endogenous insulin secretion.
DeFronzo et al. has reported the euglycemic glucose clamp method which can evaluate the time dependent changes of glucose utilization and may give a more reliable estimation for insulin sensitivity. One disadvantage of this technique is that this method requires frequent determinations of blood glucose and adjustment of infusion rate of glucose. It is necessary for the operator to make empirical corrections for the infusion rate of glucose in order to obtain a constant clamped glucose level during the entire examination period. In order to obtain the more precise, easier and objective results for estimation, we have attempted to develop a computerized glucose clamp method.

From the Third Department of Medicine, Shiga University of Medical Science, Ohtsu, and

*Kyoto Daiichi Kagaku Co., Kyoto.

Received for publication April 28, 1986.

Reprint request to: Yutaka Harano, MD, The Third Department of Medicine, Shiga University of Medical Science, Tukinowamachi, Seta, Ohtsu, Shiga 520-21, Japan. 


\section{SUBJECTS AND METHODS}

\section{Subjects}

Seven healthy volunteers (7 males) with no medication and no family history of diabetes, aged between 24-66 years old (mean \pm SEM; $42.4 \pm$ 7.0 ), whose body weight were within $\pm 15 \%$ of ideal body weight (mean \pm SEM; $94.7 \pm 2.9$ of $\%$ ideal body weight), were studied for insulin sensitivity using glucose clamp method.

Twenty-seven NIDDM (19 males, 8 females), aged between $41-74$ years old (mean \pm SEM, 57.4 \pm 9.4) were also studied. Fasting plasma glucose levels were between 70-212 mg/dl (mean \pm SEM; $116.6 \pm 14.8), \mathrm{HbA}_{1}$ levels were between 6$15.6 \%$ (mean \pm SEM; $8.53 \pm 0.39$ ). Fourteen were treated under diet therapy (group D), 8 on sulfonyl urea (group SU), 5 with insulin therapy (group I). The average FPG, duration of diabetic state, and the value of $\mathrm{HbA}_{1}$ are slightly different from each other group, but not significant. Other profiles of the subjects studied are shown in Table 1

\section{METHODS}

\section{General Procedure}

Subjects were studied in the supine position in the morning after overnight fasting. A silicone catheter with double lumen was inserted into an antecubital vein for blood sampling at the rate of $3 \mathrm{ml} / \mathrm{hr}$. Blood glucose concentration was measured continuously by Glucose Monitor (Kyoto Daiichi Kagaku Co., Kyoto).

The glucose solution containing $\mathrm{KCl}(10 \mathrm{mEq} / \mathrm{l})$ was infused using infusion pumps, TFV-1100 (Nihon Kohden Co.) via butterfly needle placed in a cubital vein opposite to that for glucose monitoring according to the algorithm described below using personal computer (Sharp).

\section{Insulin Infusion}

Human Insulin (provided from Novo Co.) was infused at the rate of $0.77 \mathrm{mU} / \mathrm{kg}$ body weight/ min using portable pump (My Fuser, Nikkiso Co.) for at least 2 hours. Prior to the insulin infusion, a bolus insulin was given intravenously $(5.8 \mathrm{mU} / \mathrm{kg}$ body weight). For diabetic patients who had been treated with insulin for more than 50 days, fish insulin (mixture of bonito and tunny insulin, provided from Mr. Koga, Shimizu Pharmaceutical Co., Shizuoka, Japan) was used in order to minimize cross reaction with endogenously produced insulin antibody ${ }^{11)}$.

\section{Glucose Infusion}

Twelve percent solution of glucose with 10 $\mathrm{mEq} / \mathrm{l} \mathrm{KCl}$ was infused at the rate calculated in a following formula.

\section{Initial Injection}

Initial glucose infusion rate was determined as following formula.

a) Hyperglycemic state [blood glucose value $>$ $\mathrm{TG}+10]$

Glucose infusion was started when the estimated blood glucose 8 minutes after the time $t$ was below the target glucose. The intial glucose infusion rate was obtained from the following formula.

$-\mathrm{SL} \times \mathrm{KH}$

(SL is $\frac{\mathrm{dg}(\mathrm{t})}{\mathrm{dt}}$, while $\mathrm{g}(\mathrm{t})$ is blood glucose level at time t. $\mathrm{KH}$ is the initial parameter and arbitrary 1 was used routinely. TG is the target glucose

Table 1. Patient profile for the study of computerized glucose clamp method

\begin{tabular}{lccccccc}
\hline & Number & $\begin{array}{c}\text { Age } \\
\text { (years) }\end{array}$ & Sex & $\begin{array}{c}\text { Duration } \\
(\text { year })\end{array}$ & $\begin{array}{c}\% \text { IBW } \\
(\%)\end{array}$ & $\begin{array}{c}\text { FPG } \\
(\mathrm{mg} / \mathrm{dl})\end{array}$ & $\begin{array}{c}\mathrm{HbA}_{1} \\
(\%)\end{array}$ \\
\hline Normal & 7 & $40.4 \pm 7.0$ & $7 \mathrm{M}$ & - & $94.7 \pm 2.9$ & $83.8 \pm 7.6$ & - \\
NIDDM & 27 & $57.4 \pm 1.8$ & $\begin{array}{c}16 \mathrm{M} \\
11 \mathrm{~F}\end{array}$ & $7.80 \pm 1.30$ & $100.5 \pm 2.0$ & $116.6 \pm 14.8$ & $8.53 \pm 0039$ \\
Diet & 14 & $55.1 \pm 3.0$ & $9 \mathrm{M}$ & $5.20 \pm 1.44$ & $102.2 \pm 1.7$ & $127.6 \pm 29.5$ & $8.49 \pm 0.64$ \\
SU & 8 & $60.9 \pm 3.0$ & $\begin{array}{l}4 \mathrm{~F} \\
4 \mathrm{~F}\end{array}$ & $9.66 \pm 3.47$ & $101.7 \pm 5.5$ & $98.0 \pm 4.2$ & $9.16 \pm 0.75$ \\
Ins. & 5 & $57.8 \pm 4.3$ & $3 \mathrm{M}$ & $12.40 \pm 3.23$ & $94.8 \pm 8.4$ & $115.8 \pm 10.3$ & $7.23 \pm 0.47$ \\
\hline
\end{tabular}


value $(\mathrm{mg} / \mathrm{dl}))$.

b) Hypoglycemic state [blood glucose value $\leqq$ $\mathrm{TG}+10]$

Glucose infusion was started at once. The glucose infusion rate of the initial infusion was obtained from the followings.

$(\mathrm{TG}+10-\mathrm{BG}) \times \mathrm{KL}$

( $\mathrm{KL}$ is the initial parameter and the 1 was used routinely. BG is the blood glucose value).

Subsequent glucose infusion rate

$$
\mathrm{GI}(\mathrm{t})=\mathrm{G} 1(\mathrm{t})+\mathrm{G} 2(\mathrm{t})+\mathrm{G} 3(\mathrm{t})
$$

$A$ rate of glucose infusion was determined by the above formula.

$\mathrm{GI}(\mathrm{t})$ : glucose infusion rate $(\mathrm{mg} / \mathrm{kg}$ body weight/ $\min$ ) at time $t$.

$$
\mathrm{G} 1(\mathrm{t})=\left(\frac{\mathrm{K} 1}{100}\right)(\mathrm{TG}-\mathrm{PBG}(\mathrm{t}))
$$

PBG(t): predicted blood glucose concentration $(\mathrm{mg} / \mathrm{dl})$ at 4 minutes after the Time $\mathrm{t}$ calculated from the regression line of the past seven data.

$$
\mathrm{G} 2(\mathrm{t})=-\left(\frac{1}{2}\right)\left(\frac{\mathrm{K} 2}{100}\right)\left(-\frac{\mathrm{dg}(\mathrm{t})}{\mathrm{dt}}\right)
$$

$\frac{\mathrm{dg}(\mathrm{t})}{\mathrm{dt}}$ : Slope of blood glucose $(\mathrm{mg} / 2 \mathrm{~min})$.

$$
\mathrm{G} 3(\mathrm{t})=\mathrm{K} 3 \frac{1}{\mathrm{a}} \int_{\mathrm{t}-\mathrm{a}}^{\mathrm{t}} \mathrm{G}(\mathrm{t}) \mathrm{dt}
$$

$\mathrm{K} 1$, $\mathrm{K} 2$ and $\mathrm{K} 3$ are the constants and usually $\mathrm{K} 1=5, \mathrm{~K} 2=12$ and $\mathrm{K} 3=100$ are used.

$\frac{1}{a} \int_{t-a}^{t} G(t) d t$ is a mean value of glucose infused prior to the time $\mathrm{t}$ (usually 4 minutes). Occasional manual change of $\mathrm{K}$ values were needed for strict glucose clamp in some subjects.

\section{Glucose Clearance}

Glucose clearance rate was determined by the following formula:

Glucose Clearance $=$

$$
(\mathrm{ml} / \mathrm{kg} / 10 \mathrm{~min})
$$

GI $\times 10$

plasma glucose at steady state $(\mathrm{mg} / \mathrm{dl})$

Target glucose concentration was chosen as 100 $\mathrm{mg} / \mathrm{dl}$ when the fasting blood glucose was over 100 $\mathrm{mg} / \mathrm{dl}$, and fasting blood glucose level when under $100 \mathrm{mg} / \mathrm{dl}$.

\section{Determination of Substrates}

Blood was drawn separately at $0,30,120 \mathrm{~min}$ to determine the levels of glucose $\mathrm{e}^{13)}$, FFA, triglyceride, cholesterol and insulin ${ }^{14)}$.

\section{RESULTS}

Computerized glucose clamp study in normal subjects

Time-dependent changes of the glucose infusion rate and the monitored blood glucose curve in normal typical case is shown in Fig. 1. In normal subjects, glucose infusion was initiated immediately. The glucose infusion rate has shown a small peak at 20-30 $\mathrm{min}$, then decreased, and reached to the steady state between 60 and $120 \mathrm{~min}$. Mean blood glucose levels during the last $60 \mathrm{~min}(88.7$ $\pm 7.5 \mathrm{mg} / \mathrm{dl}$ ) did not differ significantly from target glucose concentrations $(84.1 \pm 3.4 \mathrm{mg} / \mathrm{dl})$, and the coefficient of variation of the blood glucose values was $6.3 \pm 1.7(\%)$, which was within the satisfactory limit (Table 2).

A glucose infusion rate did not follow a smooth hyperbolic line, but showed some bumps for the initial 30-60 $\mathrm{min}$. However, these bumps did not seriously affect the glucose utilization rate at steady state which was usually obtained around

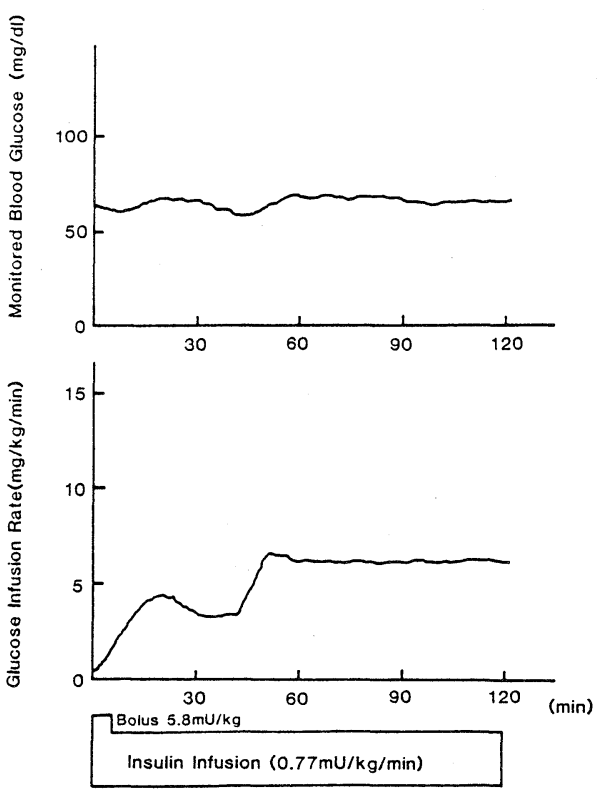

Fig. 1. A typical computerized glucose clamp study in normal (Case M.T.). 
Harada et al

Table 2. The computerized glucose

\begin{tabular}{lcccc}
\hline & $\begin{array}{c}\text { Number of } \\
\text { Subjects }\end{array}$ & $\begin{array}{c}\text { Glucose } \\
\text { Utilization } \\
(\mathrm{mg} / \mathrm{kg} / \mathrm{min})\end{array}$ & $\begin{array}{c}\text { Glucose } \\
\text { Clearance } \\
(\mathrm{mg} / \mathrm{kg} / 10 \mathrm{~min})\end{array}$ & $\begin{array}{c}\text { Total } \\
\text { Glucose } \\
\text { Utilization } \\
(\mathrm{mg} / \mathrm{kg})\end{array}$ \\
\hline Normal & 7 & $7.59 \pm 0.85$ & $90.5 \pm 8.2$ & $658.5 \pm 66.2$ \\
NIDDM & 27 & $4.13 \pm 0.32^{* * *}$ & $42.3 \pm 3.4^{* * *}$ & $369.4 \pm 37.8^{* * *}$ \\
Diet & 14 & $4.98 \pm 0.43^{* * *}$ & $50.7 \pm 4.8^{* * *}$ & $442.5 \pm 58.1^{*}$ \\
SU & 8 & $4.16 \pm 0.33^{* * *}$ & $42.9 \pm 4.4^{* * *}$ & $399.4 \pm 48.6^{* *}$ \\
Ins. & 5 & $2.00 \pm 0.23^{* * *}$ & $20.8 \pm 2.5^{* * *}$ & $167.1 \pm 25.0^{* * *}$ \\
\hline
\end{tabular}

$*_{\mathrm{p}}<0.05, * * \mathrm{p}<0.01, * * * \mathrm{p}<0.001$. v.s. normal

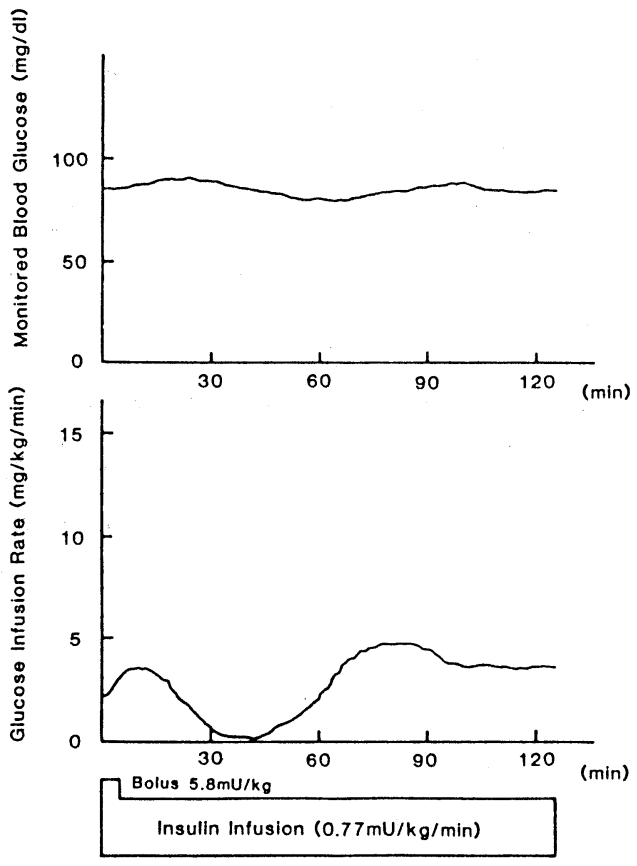

Fig. 2a. A typical computerized glucose clamp study in NIDDM (Case O.K.) on diet.

at 2 hours after the initiation of insulin infusion. Steady state glucose infusion rate and glucose clearance was $7.59 \pm 0.85(\mathrm{mg} / \mathrm{kg} / \mathrm{min}), 90.5 \pm$ $8.2(\mathrm{ml} / \mathrm{kg} / 10 \mathrm{~min})$, respectively. Steady state plasma insulin concentration averaged $48.2 \pm 3.1$ $(\mu \mathrm{U} / \mathrm{ml})$.

\section{Computerized glucose clamp study in NIDDM}

Time-dependent changes of the glucose infusion rate and monitored blood glucose levels in typical subjects on diet, SU and insulin are shown in Figs. 2a, 2b, 2c, respectively. Target glucose levels were attained within $40 \mathrm{~min}$ in all cases. Until then,

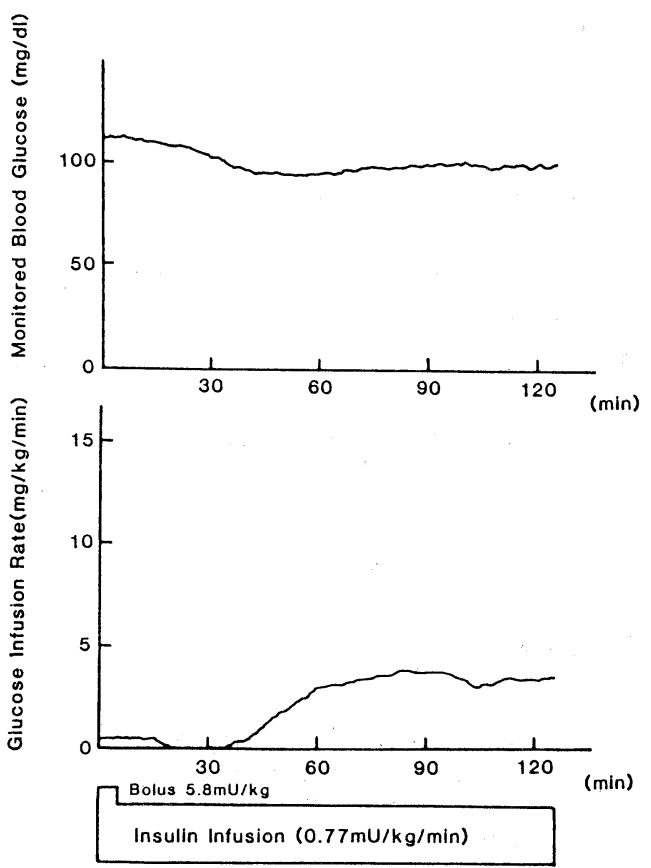

Fig. 2b. A typical computerized glucose clamp study in NIDDM (Case M.H.) on SU.

no or computerized glucose load was infused. In diabetic subjects, especially treated with SU and insulin, the glucose infusion rate showed smaller bumps than in normal subjects (Figs. 2b, 2c). Mean blood glucose levels during the last $60 \mathrm{~min}$ in NIDDM $(92.3 \pm 2.1 \mathrm{mg} / \mathrm{dl})$ did not differ significantly from target glucose concentrations $(92.9$ $\pm 2.0 \mathrm{mg} / \mathrm{dl}$ ), and the coefficients of variation of the blood glucose levels was $3.8 \pm 0.5,4.1 \pm 0.9$, $3.0 \pm 0.9(\%)$ in diabetic subjects with diet, SU or insulin treatment (Table 2), which were within satisfactory limit. The average of the steady state 
clamp study in Normal and NIDDM

\begin{tabular}{ccccc}
\hline $\begin{array}{c}\text { CV } \\
(\%)\end{array}$ & $\begin{array}{c}\text { Target } \\
\text { Glucose } \\
(\mathrm{mg} / \mathrm{dl})\end{array}$ & $\begin{array}{c}\text { Average of } \\
\text { Measured } \\
\text { Glucose }\end{array}$ & $\begin{array}{c}\text { Time Reached to } \\
\text { Steady State } \\
(\mathrm{min})\end{array}$ & $\begin{array}{c}\text { SSPI } \\
(\mu \mathrm{U} / \mathrm{ml})\end{array}$ \\
\hline $6.3 \pm 1.7$ & $84.1 \pm 3.4$ & $88.7 \pm 7.5$ & $119.1 \pm 4.4$ & $48.2 \pm 3.1$ \\
$3.7 \pm 0.3$ & $92.9 \pm 2.0$ & $92.3 \pm 2.1$ & $135.2 \pm 3.5$ & $57.8 \pm 7.1$ \\
$3.8 \pm 0.5$ & $89.9 \pm 3.4$ & $88.4 \pm 3.4$ & $139.3 \pm 5.3^{* *}$ & $47.1 \pm 3.3$ \\
$4.1 \pm 0.9$ & $97.9 \pm 1.6$ & $97.3 \pm 2.1$ & $133.1 \pm 4.8$ & $52.9 \pm 4.1$ \\
$3.0 \pm 0.9$ & $93.0 \pm 5.5$ & $94.6 \pm 6.1$ & $123.2 \pm 10.5$ & - \\
\hline
\end{tabular}

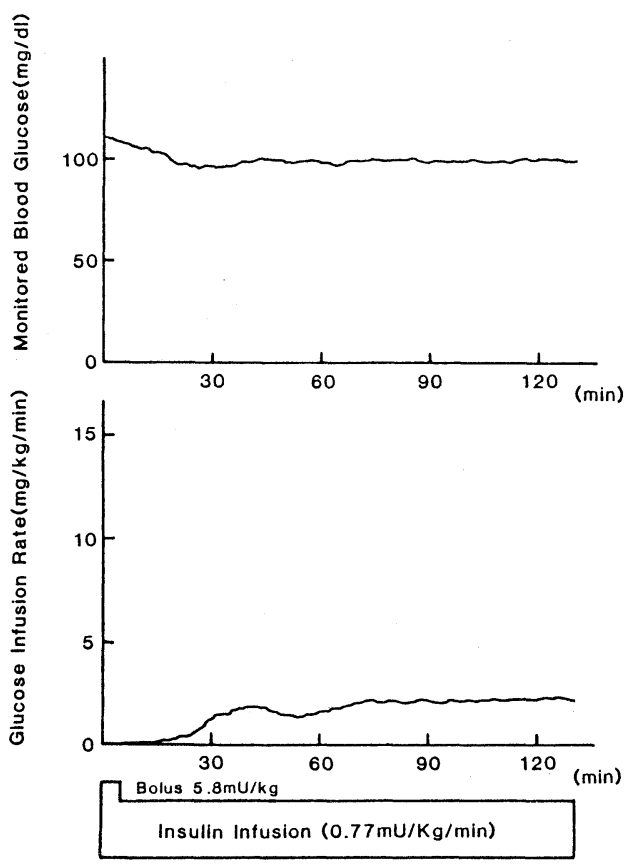

Fig. 2c. A typical computerized glucose clamp study in NIDDM (Case A.S.) on insulin.

glucose infusion rate was $4.98 \pm 0.43,4.16 \pm 0.33$ and 2,00 \pm 0.23 in NIDDM treated with diet, SU and insulin, respectively. It is to be noted that diabetic subjects treated with insulin exhibited the lowest insulin sensitivity, while diet and SU did not show significant difference. Mean glucose clearance in NIDDM treated with diet therapy, $\mathrm{SU}$, insulin were $50.7 \pm 4.8,42.9 \pm 4.4,20.8 \pm$ $2.5(\mathrm{ml} / \mathrm{kg} / 10 \mathrm{~min})$, respectively, which were significantly lower than normal. Steady state plasma insulin concentration averaged $57.8 \pm 7.1$ $(\mu \mathrm{U} / \mathrm{ml})$ in NIDDM, which was not statistically different from that in normal subjects.

\section{DISCUSSION}

In this paper, we have demonstrated a new, simplified computerized glucose clamp method for estimation of glucose utilization rate at the physiological level of plasma insulin (40-60 $\mu \mathrm{U} / \mathrm{ml})$. This program is not based on the glucose kinetic model as previously reported ${ }^{6,8,10}$ ), but simply based on the mathematical algorithm using values of blood glucose concentration, desired level and the rate of change of glucose concentration.

The blood glucose was clamped successfully at target glucose concentration and $\mathrm{CV}$ of the monitored blood glucose was less than $6.5 \%$. This indicates that adherence of blood glucose at the target glucose is well within the range obtained with manual minute to minute manipulation. A steady state glucose infusion (utilization) rate was obtained at 2-3 hours after insulin infusion. In some subjects, whose insulin sensitivity was high, the blood glucose was labile and $\mathrm{CV}$ was not low enough as shown in the normal subjects. In these subjects, the curve showed sign curve. In order to counteraccount for the 4 minutedelay of glucose monitoring, perdicted glucose values by linear regression were used. However, still some initial bumps were observed. In the study performed by the manual adjustment of glucose infusion rate, less bumps were observed indicating that human anticipotation would give the better smooth curve of glucose infusion compared with the computerized program. Other reports using computer method also failed to obtain the smooth curve ${ }^{8)}$. The present method with less variation of clamped glucose values is 
thought to be satisfactory for the clinical estimation of glucose utilization rate at the steady state (90-150 min). The computerized method with only occasional manual adjustment of $\mathrm{K}$ values is much easier than the tedious manual performance of glucose determination and glucose infusion rate.

\section{REFERENCES}

1) Himsworth HP: Diabetes mellitus. Lancet 1: 127, 1936.

2) Reaven GM, Bernstein R, Davis B, et al: Nonketotic diabetes mellitus; insulin deficiency or insulin resistance? Am J Med 60: 80, 1976.

3) Shen SW, Reaven GM, Farquhar JW: Comparison of impectance to insulin-mediated glucose uptake in normal subjects and in subjects with latent diabetes. J Clin Invest 49: 215, 1970.

4) Harano, Y, Ohgaku S, Hidaka H, et al: Glucose insulin and somatostatin infusion for the determination of insulin sensitivity. J Clin Endocrinol Metab 45: 1124, 1977.

5) Harano $Y$, Hidaka $H$, Takatsuki $K$, et al: Glucose, insulin and somatostatin infusion for the determination of insulin sensitivity in vivo. Metabolism 27: 1449,1978

6) DẹFronzo RA, Tobin JD, Andres R: Glucose clamp technique; a method for quantifying insulin secretion and resistance. Am J Physiol 237: E214, 1979.

7) Harano Y, Ohgaku S, Kosugi K, et al: Clinical significance of altered insulin sensitivity in diabetes mellitus assessed by glucose, insulin and somatostatin infusion. J Clin Endocrinol Metab 52: 982, 1981.

8) Greenfield MD, Doberne L, Kramer F, et al: Assessment of insulin resistance with0he insulin suppression test and englycemic clamp. Diabetes 30: 387,
1981.

9) Reaven G, Bernstein R, Davis B, et al: Nonketotic Diabetes Mellitus: Insulin Deficiency or Insulin Resistance? Am J Med 60: 80, 0000.

10) Insel PA, Liljenquest JE, Tobin J, et al: Insulin control of glucose metabolism in man. J Clin Invest 55: 1057, 1975 .

11) Karlsson F, Harrison LC, Kahn CR, et al: Subpopulations of antibodies directed against evolutionarily conserved regions of the insulin molecule in insulin-treated patients. Diabetologia 23: 488, 1982.

12) Verdonk CA, Rizza RA, Gerich JE: Effects of plasma glucose concentration on glucose utilization and glucose clearance in normal man. Diabetes 30: 535,0000 .

13) Hoffman WS: A rapid photoelectric method for the determination of glucose in blood and urine. J Biol Chem 120: 51, 1937.

14) Hales $\mathrm{CN}$ and Randle PJ: Immunoassay of insulin with insulin antibody precipitate. Biochem $\mathrm{J}$ 88: 137, 1963.

15) Pacini G, Finegood DT, Bergman RN: A minimalmodel-based glucose clamp yielding insulin sensitivity independent of glycemia. Diabetes 31: 432, 1982.

16) Anders R, Swerdloff RS, Pozefsky T, et al: Manual feedback technique for control of blood glucose concentration. In Automation in Analytical Chemistry. Skggs LT Jr, New York, Mediac Inc, 1966, p 486.

17) Norwich KH, Fluker G, Anthony J, et al: The development of Glucose Clamp. Metabolism 24: $1221,1975$.

18) Kline NS, Shimano E, Stearns H, et al: Technique for automatic in vivo regulation of blood sugar. Med Res Eng 00: 14, 1968. 